\title{
The Characteristics of Suicide in Gunungkidul Indonesia
}

\author{
F.A Nurdiyanto*, Siti Jaroah \\ Faculty of Psychology, Gadjah Mada University, Sleman, Indonesia \\ *corresponding author, e-mail: nurdiyanto@mail.ugm.ac.id
}

Received: 06/04/2020; published: 29/09/2020

\begin{abstract}
Background: The suicide incidents in Gunungkidul did not decrease according to previous reports. This research was conducted to described suicide trends in Gunungkidul from 2012 to 2019 and their characteristics. Method: The research used retrospective approach by analyzing suicide data from local police based on demography (sex, occupation, age, residence) and the methods of suicide. We analyzed the suicide trends in the last 8 years. Results: The result of the descriptive analysis shows that suicide in Gunungkidul has the following characteristics: 1) mostly done by male than female, 2 ) farmers, 3 ) elderly (>60 years old) and adults (36-60 years old), and 4) hanging as the popular method to completed suicide. Conclusion: This research suggests that suicide prevention should be done to people with suicide risks, especially the elderly, and promotes suicide prevention to society. We proposed implementing community-based to reduce the accessibility of lethal methods of suicide.
\end{abstract}

Keywords: suicide; retrospective study; Gunungkidul regency

Copyright $\odot 2013$ Universitas Ahmad Dahlan. All rights reserved.

\section{Introduction}

Suicide is a major global problem and needs serious attention. WHO records death by suicide has reached $10.5 \%$ globally and claims $>800,000$ lives annually (1). Suicide rates are noticeably high in low-mid income countries (79\%); with the highest occurrence, which reaches $13.4 \%$, in Southeast Asia. Suicide is the second leading cause of death after road accident among individuals between the ages of 15 and 29. Individuals at this age suffer suicidal tendencies again when they reach into adulthood (2).

Suicide rates are tend to be dynamic in Indonesia. WHO recorded the prevalence of suicide in 2010 showing the lowest rate of $1.8 \%$. It then increased to $4.3 \%$ in 2014 and decreased again by $3.7 \%$ in 2016 (1). Although the report showed that the trend of suicide has decreased, WHO warned that suicide would become a ticking time bomb if there is no prevention strategies and surveillance systems. Besides, many doubted suicide data in Indonesia since there is no national suicide registration system (3). There is a high probability that many cases of suicide are not identified. One area in Indonesia with a high suicide rate is Gunungkidul $(4,5)$. For decades it can be said that the incidence of suicide in Gunungkidul has not decreased. According to Andari's report (2017) there were 330 suicides cases from 2003 to 2012 (6).

The cause of suicide in Gunungkidul is not certain, but it is suspected that it involved multiple factors. Most people of Gunungkidul have long believed that suicide is nothing but the effect of pulung gantung (5). Apart from that, other minor factors were also mentioned, such as chronic illness, social \& geographic isolation, drought \& barren land, and low education levels. The cultural approach was also applied by several researchers who found and suspected that the decision to commit suicide is affected by a) shame (wirang), b) social costs, and c) strong social ties $(5,6)$. 
The social relations of the people of Gunungkidul are built by emphasizing the strong social integration of its members. People's valuation as ora umum or uncommon (not following the common sense in society) causes negative emotion reaction in the form of wirang (shame). Shame for the Javanese is both a feeling and an act of self-control over manners and social norms (7). However, persons who feel that their dignity is humiliated will have strong negative emotions. In this case wirang involves a psychological condition in the form of a threat to self-esteem, because those individual actions are considered inconsistent with social ethics and morals. Suicide is then considered as self-esteem enforcement mechanisms. Mental health issues began to be mentioned to explain the phenomenon of suicide in Gunungkidul. Based on the police investigation report, the cause of suicide in Gunungkidul related to depression and mental illness (52\%), chronic illness $(24 \%)$, financial problems $(5 \%)$, family problems $(4 \%)$, and others (15\%) $(6)$. Even though the data is weak because the mode concluded by the police is a trigger for suicide and not a causative factor, it can indicate a shift in discourse on suicide into psychosocial and health problems (8-10). Suicide victims previously showed indications of neglected mental illness, such as prolonged sadness, feelings of uselessness, confusion, withdrawal, and being quiet.

The problem of suicide needs serious conduct, but the various efforts which have been made are not optimal yet. The kabupaten (district) government has issued a regulation on the preventing and handling of suicide through the Peraturan Bupati Gunungkidul Number 56 of 2018. Through this policy, it is expected to reduce the suicide rate by involving government officials and the community. However, the implementation of these regulations still faces problems, including but not limited to a) the stigma and stereotypes of suicide; people do not realize that suicide is a "humanitarian disaster", b) limited professional human resources (psychiatrists, psychologists, counselors, social workers), c) not evenly distributed training or skills development for volunteers, d) insensitive to signs of suicide, e) inaccuracy in management of suicide data.

So far, data on suicide has been accessed through the police, which handle suicide reports through criminal or forensic investigations which means that not all suicides are reported and recorded. The credibility of suicide data has a major contribution to the effort to tackle suicide cases $(8,11)$. Incomplete or limited information can complicate the quantification of death and its various consequences. The government will also find it difficult to set a suicide prevention agenda (12). In addition, complete information can provide certainty in assessing the effectiveness of programs and public accountability. This study was conducted to present descriptive data on suicides that occurred in Gunungkidul from 2012-2019 which were reviewed based on demographics, methods of suicide, and location. This research is expected to provide new information about the phenomenon of suicide in Gunungkidul.

\section{Method}

This design of this research was a quantitative method on secondary data using retrospective study approach. This approach is used to determine the trend of incidents using past data. This study analyzed data on suicides in Gunungkidul Regency from 2012 to 2019, totaling 242 cases. Suicide data were obtained from the Gunungkidul Resort Police, which included information on the kecamatan (sub-district), age, sex, occupation, and methods of suicide. The police together with local health officials have the authority to identify suicides based on criminal or forensic investigation protocols on unnatural deaths; whether the deaths have the potential for criminal acts or are purely suicides. Data analysis was conducted using quantitative descriptive analysis and crosstab. Quantitative descriptive analysis was used to determine the trend of suicide based on the suicide victims' sex 
category, age, occupation and suicide method. Crosstab analysis was used to determine the trend of suicide cases based on the frequency of age categories and sub-districts. In addition, researchers compared the data of the suicide cases with the population of Gunungkidul to determine the prevalence rate of suicide.

\section{Results and Discussion}

\subsection{Results}

Table 1 shows the demographic data of suicide victims in Gunungkidul. In the 20122019 period, 242 suicides had occurred. During this period, suicide was mostly committed by men $(67.34 \%)$, of the elderly $(49.17 \%)$, and most of the victims of suicide were farmers $(74.79 \%)$. Moreover, hanging $(95.04 \%)$ is the most used method of suicide compared to other methods.

Table 1. Characteristics of Suicide Victims in Gunungkidul 2012-2019

\begin{tabular}{lcc}
\hline Karakteristik & \multicolumn{2}{c}{ Total } \\
\cline { 2 - 3 } Sex & $\mathbf{n}$ & $\%$ \\
Male & 163 & 67.36 \\
Female & 78 & 32.23 \\
Unknown & 1 & 0.41 \\
Age & & \\
Adolescent (12-19) & 4 & 1.65 \\
Early adulthood (20-35) & 28 & 11.57 \\
Adulthood (36-60) & 90 & 37.19 \\
Elderly (>60) & 119 & 49.17 \\
Unknown & 1 & 0.41 \\
Occupation & 181 & 74.79 \\
Farmer & 28 & 11.57 \\
General employee & 11 & 4.55 \\
Casual worker & 7 & 2.89 \\
Entrepreneur & 6 & 2.48 \\
Housemaid & 2 & 0.83 \\
Student & 1 & 0.41 \\
Retired civil servants & 6 & 2.48 \\
Unknown & & \\
Suicide Methods & 230 & 95.04 \\
Hanging & 7 & 2.89 \\
Jumping & 4 & 1.65 \\
Drinking poison & 1 & 0.41 \\
Unknown & &
\end{tabular}

Table 2 shows that the incidence of suicide occurred in all sub-districts in Gunungkidul, but the variation in incidence occurred from early adulthood to the elderly. Suicide by the elderly mostly occurred in the Sub-districts of Karangmojo, Panggang, Playen, Semanu, Semin, Tanjungsari, Tepus, and Wonosari. Meanwhile, the incidents of suicide in adulthood occurred more in Semanu, Semin, Tepus and Wonosari Sub-districts. During those 8 years several sub-districts have a high incidence of suicide; including Tepus (25 cases), Wonosari (24 cases), Semin (23 cases), Semanu (22 cases), and Playen (22 cases). During the period 2012-2019, the Police recorded a total of 242 suicides $(M=30.25, S D=5.52)$. 
Tabel 2. Crosstab Suicide in Gunungkidul by Age Category and District

\begin{tabular}{lcccccc}
\hline Sub-district & \multicolumn{5}{c}{ Age } & Total \\
\cline { 2 - 5 } & $\begin{array}{c}\text { Adolescent } \\
(12-19)\end{array}$ & $\begin{array}{c}\text { Early } \\
\text { adulthood } \\
(20-35)\end{array}$ & $\begin{array}{c}\text { Adulthood } \\
(36-60)\end{array}$ & $\begin{array}{c}\text { Elderly } \\
(>60)\end{array}$ & Unknown & \\
\hline Gedangsari & 0 & 1 & 4 & 3 & 0 & 8 \\
Girisubo & 1 & 2 & 5 & 5 & 0 & 13 \\
Karangmojo & 0 & 1 & 6 & $9^{*}$ & 0 & 16 \\
Ngawen & 0 & 2 & 6 & 6 & 0 & 14 \\
Nglipar & 0 & 0 & 4 & 6 & 0 & 10 \\
Paliyan & 0 & 0 & 3 & 0 & 0 & 3 \\
Panggang & 0 & 0 & 5 & $7^{*}$ & 0 & 12 \\
Patuk & 0 & 2 & 2 & 4 & 1 & 9 \\
Playen & 1 & 4 & 5 & $12^{*}$ & 0 & 22 \\
Ponjong & 0 & 4 & 2 & 6 & 0 & 12 \\
Purwosari & 0 & 0 & 1 & 4 & 0 & 5 \\
Rongkop & 1 & 0 & 0 & 3 & 0 & 4 \\
Saptosari & 0 & 1 & 1 & 4 & 0 & 6 \\
Semanu & 1 & 2 & $9^{*}$ & $10^{*}$ & 0 & 22 \\
Semin & 0 & 4 & $8^{*}$ & $11^{*}$ & 0 & 23 \\
Tanjungsari & 0 & 1 & 5 & $8^{*}$ & 0 & 14 \\
Tepus & 0 & 2 & $13^{*}$ & $10^{*}$ & 0 & 25 \\
Wonosari & 0 & 2 & $11^{*}$ & $11^{*}$ & 0 & 24 \\
Total & 4 & 28 & 90 & 119 & 1 & 242 \\
\hline
\end{tabular}

*high $>6.15, M=2.69, S D=3.46$

This study also estimated the prevalence rate of suicide using secondary data from Gunungkidul Police Resort by comparing population data from BPS Gunungkidul. Graph 1 shows that the highest suicide rate occurred in 2012 (5.78) and the lowest occurred in 2014 (2.83).

Graph 1. The prevalence of suicide in Gunungkidul 2012-2019

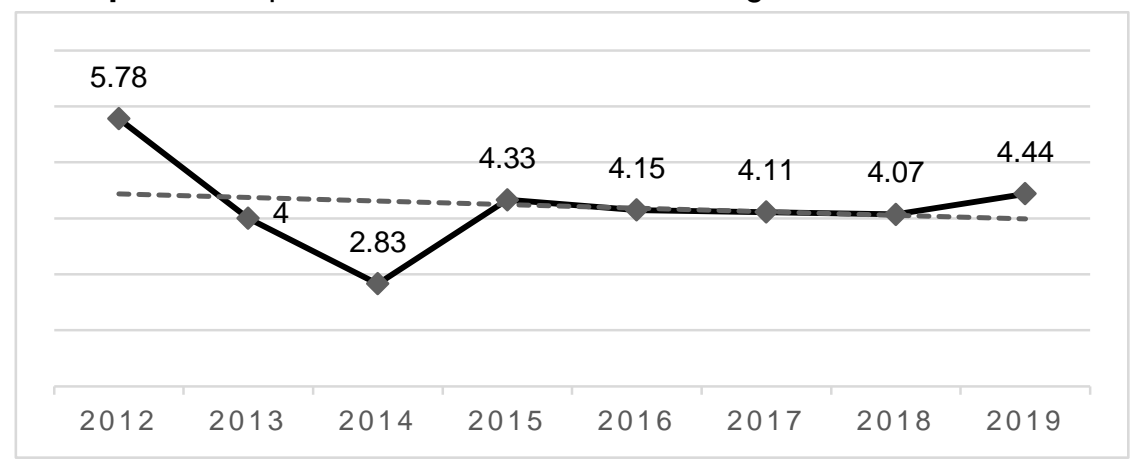

\subsection{Discussion}

This study found that the incidence of suicide in Gunungkidul was characterized by gender which was dominated by men; b) the victims were mostly elderly and adulthood groups; c) based on the type of work, the majority of victims who hanging themselves worked as farmers and d) hanging is the most popular method to commit suicide. Suicide in Gunungkidul has long been suspected as a result of geographical conditions and economic pressure. However, until now there has been no investigation that shows how the interaction of poverty and barren conditions leads to suicide. However, accusing poverty and drought as the cause of the high suicide rate in Gunungkidul is nothing but premature assumption. On the other hand, the poverty rate in Gunungkidul according to the BPS report shows a decreasing pattern over the last decade (13). 
The results of this study indicate that most of the suicide committed by farmers, but that does not mean that farmers represent the reality of poverty. The study found that suicide occurred in all districts and occurred in adulthood-elderly group. Attentions should be given in identifying risk groups. Old age has specific risk factors, including neurocognitive disorders, physical illness, cognitive barriers, social exclusion, and loneliness (14-16).

The difference in suicide rates between men and women in Gunungkidul shows a similar pattern to global suicide rate. WHO estimates men have three times higher death rate by suicide compared to women $(1,17-19)$. Method choosing is thought to have a high contribution to men committing suicide (20). Men are known to have a tendency to engage in risky activities and can choose fatal methods of death, such as using firearms, hanging, or jumping $(21,22)$. On the other hand, in general men have a high tolerance for pain which is known to contribute to the guts of suicide (23). However, based on the results of this study gender differences could not be associated with the choice of suicide method. The high rate of suicide by men is thought to be based more on social expectations and demands for masculinity $(24,25)$. As the head of the household, men are expected to be able to bear all family burdens, especially concerning family welfare. When these expectations are not achieved, it can cause deep emotional conflict and lead to suicidal thoughts. The impact of this gender inequality has been strongly suspected as the cause of suicides by various global studies. However, some countries, such as China, Bangladesh, Lesotho, Morocco, and Myanmar have a pattern that shows women are more likely to commit suicide (1). This is caused by discrimination against women, domestic violence, and other psychosocial stressors due to gender bias $(26,27)$.

Hanging is a popular method of suicide in Gunungkidul. This method was chosen because of the ease of accessing the tools for suicide. Based on police data, hanging uses easily available tools such as jarit cloth, sarong, plastic raffia, or setagen cloth. These tools are relatively easier to access compared to poison, pesticides, or jumping; and it has the highest mortality rate $(18,28-30)$. Hanging oneself is the method most widely used in Australia, South Korea, and Japan $(19,30,31)$. These results are similar to studies which found a correlation between certain suicide methods and suicide rates. These studies explained that the method of suicide underwent a pattern change which was initially dominated by self-poisoning or firearms to be replaced by hanging. This change is closely related to the increasing number of suicides in these countries. Meanwhile, the hanging in Gunungkidul has not changed its trend since the 1980s. A person who has a risk of suicidal behavior should be limited to access to various objects that can be used as a medium for committing suicide $(18,32)$. Various parties explained that the choice of a suicide method was based on two factors i.e. ease of access to equipment and local socio-cultural acceptance $(9,18,29,30)$. Hanging is a major method when other alternative methods are not available or impossible to be used. Culturally, the hanging method is also considered more acceptable by the people of Gunungkidul through the myth of pulung gantung (5). A link between cultural factors and the choice of suicide method was also found in several countries, for example in India and Iran where immolation is used as one method to commit suicide, especially for women $(33,34)$.

The prevalence of suicide in Gunungkidul during the last 8 years was $4.2 \%$. This finding affirms previous research which states that the suicide rate in this district is high; above the national prevalence of suicide $(1,4)$. The existence of taboo views and stigma against suicide has made the victims' relatives or the community refuse to report the case. In addition, policies regarding suicide prevention are often formulated without paying attention to the data; or the credibility of the data which can be guaranteed. 


\section{Conclusion}

Suicide in Gunungkidul has shown a downward trend over the past 8 years. Based on gender, male groups of the elderly are more likely to commit suicide by hanging. Although the victims of suicide are mostly farmers, there is no evidence that poverty causes suicide in Gunungkidul. Suicide prevention programs should involve families and communities by prioritizing risk groups. The government needs to create a multi-sector program involving various parties, from survivors, families, community leaders, village governments, health workers, to local government officials to deal with the problem of suicide. Community-based programs targeting at-risk groups need to be a priority.

\section{References}

1. WHO. Suicide in the world: Global health estimates [Internet]. Geneva: World Health Organization; $2019 . \quad$ Available from: https://apps.who.int/iris/bitstream/handle/10665/326948/WHO-MSD-MER-19.3-eng.pdf

2. Goldston DB, Daniel SS, Heilbron N, Doyle O, Weller B, Sapyta J, et al. Suicide attempts in a longitudinal sample of adolescents followed through adulthood: Evidence of escalation. $J$ Consult Clin Psychol. 2015;83(2):253-64.

3. Kementerian Kesehatan RI. Situasi dan pencegahan bunuh diri [Internet]. Jakarta; 2019. Available from: https://pusdatin.kemkes.go.id/article/view/19103000002/situasi-danpencegahan-bunuh-diri.html

4. Wirasto RT. Suicide prevention in Indonesia: Providing public advocacy. In: The Role of Physicians in Suicide Prevention. 2012. p. 98-104.

5. Suwena IW. Bunuh diri: Sesat penandaan pulung gantung di Gunungkidul. (Doctoral dissertation). Universitas Gadjah Mada, Yogyakarta; 2016.

6. Andari S. Fenomena bunuh diri di Kabupaten Gunungkidul. Sosio Konsepsia. 2017;7(1):92107.

7. Subandi MA, Good BJ. Shame as a cultural index of illness and recovery from psychotic illness in Java. Asian J Psychiatr. 2018;34:33-7.

8. Sinyor M, Tse R, Pirkis J. Global trends in suicide epidemiology. Curr Opin Psychiatry. 2017;30(1):1-6.

9. Choo CC, Harris KM, Chew PKH, Ho RC. Does ethnicity matter in risk and protective factors for suicide attempts and suicide lethality. PLoS One. 2017;12(4):e0175752.

10. Chan LF, Thambu M. Cultural factors in suicide prevention. In: O'Connor RC, Pirkis J, editors. The international handbook of suicide prevention. 2nd Editii. John Wiley \& Sons, Ltd.; 2016. p. 541-55.

11. Bachmann S. Epidemiology of suicide and the psychiatric perspective. Int J Environ Res Public Health. 2018;15(1425):1-23.

12. Cerel J, Brown MM, Maple M, Singleton M, van de Venne J, Moore M, et al. How many people are exposed to suicide? Not six. Suicide Life-Threatening Behav. 2019;49(2):52934.

13. BPS Gunungkidul. Persentase penduduk miskin Kab. Gunungkidul [Internet]. 2019. Available from: https://gunungkidulkab.bps.go.id/subject/23/kemiskinan.html\#subjekViewTab5.

14. Suh GH, Gega L. Suicide attempts among the elderly in East Asia. Int Psychogeriatrics. 2017;29(5):707-8.

15. Conejero I, Olié E, Courtet $\mathrm{P}$, Calati R. Suicide in older adults: Current perspectives. Clin Interv Aging. 2018;13:701-12.

16. Stanley IH, Hom MA, Rogers ML, Hagan CR, Joiner TE. Understanding suicide among older adults: A review of psychological and sociological theories of suicide. Aging Ment Heal. 2016;20(2):113-22.

17. Freeman A, Mergl R, Kohls E, Székely A, Gusmao R, Arensman E, et al. A cross-national study on gender differences in suicide intent. BMC Psychiatry. 2017;17(234):1-11.

18. Choo CC, Harris KM, Ho RC. Prediction of lethality in suicide attempts: Gender matters. Omega-Journal of Death and Dying. 2019;80(1):87-103.

19. Park S. Brief report: Sex differences in suicide rates and suicide methods among adolescents in South Korea, Japan, Finland, and the US. J Adolesc. 2015;40:74-7. 
20. Siegel M, Rothman EF. Firearm ownership and suicide rates among US men and women, 1981-2013. Am J Public Health. 2016;106(7):1316-22.

21. Jamison EC, Bol KA. Previous suicide attempt and its association with method used in a suicide death. Am J Prev Med. 2016;51(5S3):S226-33.

22. Granato SL, Smith PN, Selwyn CN. Acquired capability and masculine gender norm adherence: Potential pathways to higher rates of male suicide. Psychol Men Masculinity. 2015;16(3):246-53.

23. Bauer BW, Martin RL, Allan NP, Fink-Miller EL, Capron DW. An investigation into the acquired capability for suicide. Suicide Life-Threatening Behav. 2019;49(4):1105-18.

24. Sher L. Suicide in men. J Clin Psychiatry. 2015;76(3):e371-2.

25. Oliffe JL, Han CSE, Drummond M, Sta. Maria E, Bottorff JL, Creighton G. Men, masculinities, and murder-suicide. Am J Mens Health. 2015;9(6):473-85.

26. Yip PSF, Yousuf $\mathrm{S}$, Chan $\mathrm{CH}$, Yung $\mathrm{T}, \mathrm{Wu} \mathrm{KCC}$. The roles of culture and gender in the relationship between divorce and suicide risk: A meta-analysis. Soc Sci Med. 2015;128:8794.

27. Vijayakumar L. Suicide in women. Indian J Psychiatry. 2015;57(Supp 2):S233-238.

28. Beckman K, Mittendorfer-Rutz E, Waern M, Larsson H, Runeson B, Dahlin M. Method of self-harm in adolescents and young adults and risk of subsequent suicide. $J$ Child Psychol Psychiatry. 2018;59(9):948-56.

29. Kõlves K, McDonough M, Crompton D, de Leo D. Choice of a suicide method: Trends and characteristics. Psychiatry Res. 2018;260:67-74.

30. Koo YW, Kõlves K, de Leo D. Profiles by suicide methods: An analysis of older adults. Aging Ment Heal. 2019;23(3):385-91.

31. Yoshioka E, Hanley SJ, Kawanishi Y, Saijo Y. Time trends in method-specific suicide rates in Japan, 1990-2011. Epidemiol Psychiatr Sci. 2016;25(1):58-68.

32. McKean AJS, Pabbati CP, Geske JR, Bostwick JM. Rethinking lethality in youth suicide attempts: First suicide attempt outcomes in youth ages 10 to 24. J Am Acad Child Adolesc Psychiatry. 2018;57(10):786-91.

33. Khankeh HR, Hosseini SA, Rezaie L, Shakeri J, Schwebel DC. A model to explain suicide by self-immolation among Iranian women: A grounded theory study. Burns. 2015;41(7):1562-71.

34. Rezaeian M. Self-Immolation: The literacy history between India and Iran. Iran J Psychiatry Behav Sci. 2015;9(4):e1581. 